32 Goldblatt P. Mortality and alternative social classifications. In: Goldblatt P, ed. Longitudinal study. Mortality and social organisation London: HMSO, 1990:164-90.

33 Eames M, Ben-Shlomo Y, Marmot MG. Social deprivation and premature mortality: regional comparisons across England. BMJ 1993;307:1097102.

34 Kunst AE, Mackenbach JP. The size of mortality differences associated with educational level in nine industrialised countries. Am J Public Health 1994;84:932-7.

35 The Diabetes Control and Complications Trial Research Group. The effect of intensive treatment of diabetes on the development and progression of long-term complications in insulin-dependent diabetes mellitus. N Engl J Med 1993:329:977-86.

36 United Kingdom Prospective Diabetes Study Group. United Kingdom prospective diabetes study (UKPDS) 13: relative efficacy of randomly allocated diet, sulphonylurea, insulin, or metformin in patients with newly diagnosed non-insulin dependent diabetes followed for three years. $B M$ J 1995;310:83-8.

(Accepted 16 September 1997)

\title{
Commentary: Problems in Finnish or British data-or a true difference?
}

\author{
Seppo V P Koskinen
}

Chaturvedi et al report a clear class gradient in mortality among diabetic people. In two separate data sets the death rate in the lowest socioeconomic group was roughly twice that in the highest group. In our recent study, covering the total Finnish population, we only found a non-significant $7 \%$ excess mortality among diabetic women in the lowest class compared with the highest class. ${ }^{1}$ Among diabetic men the corresponding excess was significant but still small (25\%). The discrepancy between our results and those of Chaturvedi et al may reflect deficiencies in the Finnish or British data sets, or both, or reveal a true difference between the countries.

\section{Reliability of Finnish data}

Because of our large data set, including 11215 deaths among diabetic people, random variation could have had only a minor effect on our findings. The validity of the results can, however, be questioned. As the mortality follow up was complete, we are left with the possibility that the method of case ascertainment produced biased results. In the Finnish study diabetic people were identified on the basis of entitlement to free medicines for the treatment of diabetes, while the British study also included people with diabetes treated by diet alone.

If diet treated diabetes, with better than average prognosis, is particularly common in the higher social classes, the exclusion of people with diet treated diabetes might have biased the Finnish results. ${ }^{2}$ Secondly, in the higher social classes a particularly large proportion of drug treated diabetic people may have insulin dependent diabetes, ${ }^{2}$ which tends to increase the risk of death more than non-insulin dependent diabetes. ${ }^{3}$ Thus, analysing both types of diabetes together might have artificially diluted the socioeconomic differentials in mortality. Thirdly, if a particularly large proportion of white collar employees with mild diabetes did not bother to obtain entitlement to free drugs, our results would also be biased.

All three potential sources of bias would be expected to have only a minor impact on younger diabetic people, most of whom suffer from insulindependent diabetes. As we found no socioeconomic gradient in mortality among women aged 30-49 and only a slight gradient among men of the same age, it seems unlikely that these potential sources of error played a decisive role in our results. Moreover, the national drug register data and analyses of representative population samples gave very similar estimates of the prevalence of drug treated diabetes. ${ }^{4}$

\section{Reliability of British data}

The second main question is whether the British data are reliable. Could the observed socioeconomic gradient in mortality be the result of random variation or of problems in the representativeness of the British datasets?

Random variation might have played a role in the British study. The wide confidence intervals around the mortality ratios include the corresponding values found in the Finnish study. However, the similarity of the findings from two separate datasets increases confidence in the British results.

Civil servants in London and patients of diabetes clinics in London may not be representative of the total British population. On the other hand, there is no obvious reason why the results, particularly in the Whitehall study, would be very different from those in the total population. Tables 1 and 2 in Chaturvedi et al's paper do, however, raise questions about health related selection. Among people with diabetes, heart disease seems to have been much more common in the lower than in the higher social classes. This difference is far greater than that in the non-diabetic population, and, paradoxically, diabetes seems actually to decrease the probability of heart disease in the higher social classes. Could this finding be partly explained by either early retirement or a decline in socioeconomic position among those diabetic members of the higher classes who develop heart disease? Could such selection influence the results more in Britain than in Finland, where pensioners were included in the analysis and were classified according to their former occupation?

\section{Possibility of a true difference}

The final main alternative is that there really is a true difference between the countries. In the British data there are clear socioeconomic differences in most risk factors, including smoking and blood pressure. The Finnish data do not include direct information on risk factors, but indirect evidence, based on mortality from specific causes, suggests that among people with diabetes there are only small class differences in smoking.

Further research should be carried out to assess whether (and why) the situation truly differs between
National Public Health Institute, Department of Health and Disability, Mannerheimintie 166, FIN-00300 Helsinki, Finland Seppo V P Koskinen, assistant chief physician Seppo.Koskinen@ ktl.fi 
countries. We need results from Finnish datasets that cover persons with diabetes treated by diet and include information on the disease (type, treatment, duration) and risk factors. British analyses of (pooled?) population based datasets with a large number of deaths would help in assessing the validity of the findings of Chaturvedi et al. The situation in other countries should also be studied.
1 Koskinen SVP, Martelin TP, Valkonen T. Socioeconomic differences in mortality among diabetic people in Finland: five year follow up. $B M J$ $1996 \cdot 313 \cdot 975-8$.

2 Chaturvedi N, Fuller JH. Study design and nature of diabetes may explain findings of Finnish study. BMJ 1997;314:301.

3 Wang S-L, Head J, Stevens L, Fuller JH, WHO Multinational Study Group. Excess mortality and its relation to hypertension and proteinuria iabetic patients. Diabetes Care 1996;19:305-12

4 Laakso M, Reunanen A, Klaukka T, Aromaa A, Maatela J, Pyörälä K Changes in the prevalence and incidence of diabetes mellitus in Finnish adults, 1970-1987. Am J Epidemiol 1991;133:850-7.

\title{
Randomised controlled trial of two models of care for discharged psychiatric patients
}

\author{
Peter Tyrer, Kathryn Evans, Naresh Gandhi, Alwyn Lamont, Phil Harrison-Read, Tony Johnson
}

Division of

Neuroscience and

Psychological

Medicine, Imperial

College School of

Medicine, Paterson

Centre, London

W2 1PD

Peter Tyrer,

professor of

community psychiatry

Kathryn Evans,

research assistant

Naresh Gandhi,

research fellow

Alwyn Lamont,

research fellow

Park Roval Centre

for Mental Health,

Central Middlesex

Hospital, London

NW10 7NS

Phil Harrison-Read,

consultant psychiatrist

MRC Biostatistics

Unit, Institute of

Public Health,

University Forvie

Site, Cambridge

CB2 2SR

Tony Johnson,

medical statistician

Correspondence to:

Professor Tyrer

p.tyrer@ic.ac.uk

BMJ 1998;316:106-9

\begin{abstract}
Objective: To compare the clinical outcome and costs of care of psychiatric patients allocated to community multidisciplinary teams or to hospital based care programmes after discharge from inpatient care. Design: Randomised controlled trial.

Setting: Inner London (Paddington and North Kensington) and outer London (Brent) psychiatric services.

Subjects: 155 patients with severe mental illness with a previous admission within the past 2 years.

Main outcome measures: Ratings of clinical psychopathology, depression, anxiety, and social functioning; comprehensive costs of health care. Results: Clinical outcomes were available for 133 patients and cost data for 144 patients after 1 year. The clinical outcomes of the two models of care were essentially similar, but admission to hospital was more likely in the hospital based care group and the costs of health care were $14 \%$ greater per patient than in the community group. This difference, however, was dwarfed by a twofold difference in the costs of care in the outer London services compared with those in inner London. This was explained largely by greater inpatient care for outer London patients (58 median bed days $v 18$ for inner London patients), more of which was provided by extracontractual referrals to other psychiatric hospitals as Brent had only $0.28 / 1000$ beds available for acute adult patients compared with 0.82/1000 in Paddington and North Kensington over the period of the study.

Conclusion: Aftercare by community teams for psychiatric patients with severe mental illness has a similar outcome to hospital based aftercare but with fewer admissions to hospital. When psychiatric bed requirements are insufficient for a population, however, neither form of aftercare is effective as greater use of hospital beds elsewhere swamps any advantage of community care programmes, with disintegration and discontinuity of psychiatric services leading to escalating costs.
\end{abstract}

\section{Introduction}

One of the most consistent research findings regarding mental health care for patients with severe mental illness is that assertive community care reduces the demand for hospital beds. ${ }^{1-4}$ Most studies have shown that this is achieved without any loss in efficacy of treatment. Community rather than hospital care is also much preferred by patients. ${ }^{5}$ In 1991 these findings led to the introduction of the care programme approach, ${ }^{6}$ which was intended to promote better community care. There is also accumulating evidence, however, that care programming has increased the demand for inpatient care for reasons that are unclear but which may be related to the introduction of formal procedures for case management. $^{78}$

We therefore tested the hypothesis that care programming for severe mental illness organised through community multidisciplinary teams led to greater improvement in symptoms and reduced bed use and costs compared with care programming organised by a hospital based team which had some community elements but which organised most of its care from the hospital base. The primary outcome measured was improvement in clinical symptoms, with costs as the main secondary outcome. The study was carried out at a time of considerable pressure on psychiatric beds because of rapid reduction in hospital beds, particularly in inner London.

\section{Methods}

\section{Patients}

Psychiatric inpatients aged 16-65 years under the care of four consultants (including PT and PHR) and who living in Paddington, North Kensington, and Brent were considered for the study. Inclusion criteria were diagnosis of severe mental illness (psychosis or severe non-psychotic mood disorder); at least one previous psychiatric admission within the past 3 years; and informed written consent. Recruitment took place over 1 year from March 1993, with follow up for one year.

Randomisation was carried out after research workers (KE, NG, and AL) assessed patients on the hospital wards at the time they were judged clinically fit for discharge by their consultants. An independent study coordinator then used the sealed envelope method to allocate patients to community or hospital care programmes. The appropriate service was informed that the allocation had taken place and 